\title{
The role of EGFR mutations in predicting recurrence in early and locally advanced lung adenocarcinoma following definitive therapy
}

\author{
Carlos Galvez ${ }^{2}$, Saya Jacob ${ }^{1}$, Brian S. Finkelman ${ }^{4}$, Jeffrey Zhao ${ }^{6}$, Kyle Tegtmeyer $^{6}$, \\ Young Kwang Chae ${ }^{2,3}$, Nisha Mohindra ${ }^{2,3}$, Ravi Salgia', Borko Jovanovic ${ }^{6}$, Amir \\ Behdad $^{4}$ and Victoria Villaflor ${ }^{2,3}$ \\ ${ }^{1}$ Department of Medicine, Northwestern University Feinberg School of Medicine, Chicago, IL, USA \\ ${ }^{2}$ Division of Hematology-Oncology, Northwestern University Feinberg School of Medicine, Chicago, IL, USA \\ ${ }^{3}$ Robert H. Lurie Comprehensive Cancer Center of Northwestern University, Chicago, IL, USA \\ ${ }^{4}$ Department of Pathology, Northwestern University Feinberg School of Medicine, Chicago, IL, USA \\ ${ }^{5}$ City of Hope Comprehensive Cancer Center, Los Angeles, CA, USA \\ ${ }^{6}$ Northwestern University, Chicago, IL, USA \\ Correspondence to: Victoria Villaflor, email: victoria.villaflor@nm.org \\ Keywords: non-small cell lung cancer; lung adenocarcinoma; EGFR; early; recurrence \\ Received: March 16, 2020 \\ Accepted: April 27, 2020 \\ Published: May 26, 2020
}

Copyright: Galvez et al. This is an open-access article distributed under the terms of the Creative Commons Attribution License 3.0 (CC BY 3.0), which permits unrestricted use, distribution, and reproduction in any medium, provided the original author and source are credited.

\section{ABSTRACT}

Introduction: Roughly one third of new non-small cell lung cancer (NSCLC) is diagnosed at early stages. While lobectomy can improve mortality in this group, about $30-55 \%$ of patients will experience disease recurrence. Increased investigation into the factors affecting recurrence, particularly tumor molecular genetics such as EGFR mutations, is needed.

Materials and Methods: We conducted a single-center retrospective study of $\mathbf{2 8 2}$ patients with early or locally advanced lung adenocarcinoma, with or without EGFR mutations, who underwent definitive therapy. We then assessed recurrence, stage at recurrence, time to recurrence and progression-free survival (PFS).

Results: We identified 142 patients with EGFR-mutated and 140 EGFR-wildtype lung adenocarcinoma. Overall progression between groups was equivalent at $\sim 40 \%$ at 5 years; no difference in PFS was observed at any time-point. However, among those who recurred, EGFR-mutated lung cancer had increased rates of metastatic recurrence compared to EGFR-wildtype disease ( $97 \%$ vs $68 \%, p=0.007$ ).

Conclusions: EGFR-mutated disease may be associated with a higher risk of metastatic recurrence. Molecular testing may be a promising tool for risk stratification and surveillance following definitive management for early stage disease. Future prospective, multi-center cohort studies are needed to confirm these findings and improve our understanding of how EGFR mutation contributes to prognosis and clinical outcomes.

\section{INTRODUCTION}

According to the World Health Organization (WHO), lung cancer is the most common cause of cancer and cancer related mortality in both men and women worldwide [1]. Equally important, it is associated with the highest overall mortality responsible for up to $\sim 1,760,00$ or $18.4 \%$ of all cancer deaths annually [2]. Lung cancer can be divided into small cell lung cancer (SCLC), which accounts for $\sim 15 \%$ of cases, and non-small cell lung cancer (NSCLC), which accounts for $\sim 85 \%$ of cases [3]. NSCLC can be further subclassified based on histology and presence of driver mutations. Major histologic subtypes of NSCLC include adenocarcinoma (accounting for $\sim 40-50 \%$ of all lung cancer cases), squamous cell carcinoma (accounting for $\sim 25-30 \%$ of all lung cancer cases), and large cell carcinoma (accounting for $\sim 10-15 \%$ of all lung cancer cases) $[4,5]$. 
Lung cancer is typically diagnosed at a late stage due to nonspecific or lack of symptoms (57\% of cases with metastatic disease at diagnosis). One-third of newly diagnosed lung cancers present with early stage disease (stage I or II). Furthermore, stage at initial diagnosis is statistically a strong prognostic indicator of survival. Patients with localized disease at diagnosis demonstrate a significantly higher 5-year survival compared to those with metastatic disease at diagnosis (56.3\% vs $4.7 \%$ respectively) [6]. Complete surgical resection, via lobectomy, with or without adjuvant chemotherapy as appropriate provides the best probability of cure for patients with localized disease. Patients with surgically resectable stage I NSCLC who undergo lobectomy with systematic lymph node dissection have a 5-year survival of $\sim 50-70 \%[7,8]$. Despite definitive therapy, $30-55 \%$ of patients with early NSCLC will eventually experience disease recurrence and die of their disease [9-11]. Across the medical literature, rates of disease recurrence after definitive therapy vary from $30 \%$ to $75 \%$, largely depending on stage at initial diagnosis. Median survival in pathologic stage I adenocarcinoma has been estimated between 102 107 months [12]. Furthermore, the majority of recurrences are distant with an average disease-free interval between resection and initial recurrence of 1-2 years [13-15].

With tumor molecular genetics at the forefront of precision medicine, subclassification of NSCLC based on EGFR mutation status has been paramount for predicting response to EGFR targeted therapies in unresectable advanced and metastatic disease. It is reported that up to $\sim 20 \%$ of patients with NSCLC harbor an EGFR driver mutation [16]. Furthermore, according to the PIONEER study, up to $51 \%$ of all newly diagnosed untreated Stage IIIB/ IV lung adenocarcinoma in Asia harbor an EGFR mutation [17]. With the development of targeted therapies, early identification of actionable mutations has revolutionized how we care for patients with unresectable advanced or metastatic disease. The use of anti-EGFR tyrosine kinase inhibitors (TKI) in such populations has been shown to improve overall survival while minimizing treatment toxicity [18].

Despite advances in those with unresectable disease, little is known about the prognostic implications of EGFR mutation status in early and locally advanced NSCLC amenable to definitive therapy. While identification of early or locally advanced disease portends more favorable 5 -year outcomes, the factors behind the relatively high rates of recurrence are not well understood. Further investigation of molecular tumor markers, particularly $E G F R$, as a predictor of recurrence is required. This singleinstitution retrospective study aims to better understand the implications of EGFR mutation status on localized or locally advanced NSCLC amenable to definitive therapy.

\section{RESULTS}

This study identified 142 patients with EGFRmutated adenocarcinoma who underwent definitive therapy compared to 140 EGFR-wildtype controls. The majority of these EGFR-mutated cases were diagnosed as stage I (107) in contrast to 13 cases of stage II and 22 cases of stage III. Mean age at diagnosis was overall 67 years in both groups and both groups were majority female (104 vs 96 cases respectively). Of the $E G F R$-mutated cases, $35 \%(n=47)$ presented with high risk histologic features, defined as visceral pleural invasion, lympho-vascular invasion, poor differentiation, histologic transformation, positive margins, lepidic spread or infarction/necrosis, as noted on final pathology report. This was similar to the number of EGFRwildtype cases with high risk histologic features $(37 \%$, $n=42$ ). Clinicopathologic features of patient groups based on EGFR mutation status are demonstrated in Table 1.

The majority in both groups received standard of care treatment, including cytotoxic platinum-based doublet therapy when appropriate, based on stage ( $92 \%$ vs $86 \%$ ). Notably, when analyzed by stage, stage II had dramatically fewer cases receiving standard of care treatment (definitive surgery or RT + adjuvant chemotherapy) in both groups (54\% and $46 \%$ in EGFR-mutant and EGFR-wildtype groups, respectively). The rationale for this difference was not readily available in this retrospective review, although may be partially explained by the possibility of patients getting adjuvant therapy at outside facilities.

Recurrence after definitive management in early or locally advanced adenocarcinoma occurred in 32 $E G F R$-mutated cases and 29 EGFR-wildtype cases. 30 recurrences occurred in patients with stage I disease, 9 recurrences occurred in patients with stage II disease, and 22 recurrences occurred in patients with stage III disease. No significant difference in progression free survival between $E G F R$-mutated and $E G F R$-wildtype cases was found either overall $(p>0.99)$ or at the individual time points of 1,2 , or 5 years (Table 2). We were unable to determine median PFS in the overall cohort, as $<50 \%$ individuals in our cohort progressed during the observed follow-up time. However, among those with stage III disease, median PFS was similar at 137 and 167 weeks in the EGFR-mutated and EGFR-wildtype cases, respectively.

Our study found that patients with EGFR-mutated disease had a marked increase in metastatic recurrence, compared to EGFR-wildtype disease (Table 2, Figure 1). Metastatic recurrence was defined as the presence of metastatic disease at time of first recurrence after definitive therapy. More specifically, of those that recurred, 31 (97\%) patients with $E G F R$-mutated disease recurred with distant metastasis vs. $21(68 \%)$ with EGFR WT ( $p=0.007)$. This difference was seen by all patients with early or locally advanced disease who underwent definitive therapy, but when broken down by stage, difference in metastatic recurrence by stage reached statistical significance in stage I disease only $(p=0.02)$. This discrepancy was likely due to fewer cases stage II and III disease resulting in inadequate power to detect differences between groups. 
Table 1: Comparison of patient clinicopathologic features based on EGFR mutation status

\begin{tabular}{|c|c|c|c|}
\hline & EGFR mutated & EGFR wildtype & $P$-value \\
\hline Number of Cases, $N$ & 142 & 140 & \\
\hline Stage 1 & 107 & 106 & \\
\hline Stage 2 & 13 & 13 & \\
\hline Stage 3 & 22 & 21 & \\
\hline Age at diagnosis, mean (SD) & $67.4(9.7)$ & $67.2(9.4)$ & 0.83 \\
\hline Stage 1 & $67.8(9.5)$ & $67.3(9.3)$ & 0.74 \\
\hline Stage 2 & $70.4(6.8)$ & $66.1(11.1)$ & 0.25 \\
\hline Stage 3 & $63.9(11.4)$ & $67.0(9.0)$ & 0.33 \\
\hline Gender-Female, $N(\%)$ & $104(73 \%)$ & $96(69 \%)$ & 0.46 \\
\hline Stage 1 & $77(72 \%)$ & $72(68 \%)$ & 0.62 \\
\hline Stage 2 & $9(69 \%)$ & $11(85 \%)$ & 0.64 \\
\hline Stage 3 & $18(82 \%)$ & $13(62 \%)$ & 0.26 \\
\hline $\begin{array}{l}\% \text { with high risk histologic } \\
\text { features* }\end{array}$ & $47(35 \%)$ & $42(37 \%)$ & 0.81 \\
\hline Stage 1 & $29(28 \%)$ & $27(31 \%)$ & 0.79 \\
\hline Stage 2 & $8(62 \%)$ & $8(62 \%)$ & $>0.99$ \\
\hline Stage 3 & $10(53 \%)$ & $7(54 \%)$ & $>0.99$ \\
\hline$\%$ receiving standard of care ${ }^{* *}$ & $130(92 \%)$ & $118(86 \%)$ & 0.16 \\
\hline Stage 1 & $102(95 \%)$ & $93(89 \%)$ & 0.12 \\
\hline Stage 2 & $7(54 \%)$ & $6(46 \%)$ & $>0.99$ \\
\hline Stage 3 & $21(95 \%)$ & $19(95 \%)$ & $>0.99$ \\
\hline
\end{tabular}

${ }^{*}$ High risk histologic features = visceral pleural invasion, lympho-vascular invasion, poor differentiation, histologic transformation, positive margins, lepidic spread or infarction/necrosis. ${ }^{* *}$ Standard of care defined per NCCN guidelines based on stage of disease. Stage I disease received definitive surgical management and stage II disease received surgery or radiation followed by adjuvant chemotherapy. For stage III standard of care treatment involved multi-disciplinary treatment. Patients with resectable disease received neoadjuvant chemotherapy $+/-$ radiation followed by surgery. For unresectable disease, patients received chemoradiation followed by immunotherapy.

Among cases of metastatic disease recurrence, only a minority of cases in both groups were limited to lungonly recurrence $(26 \%$ and $14 \%$ in EGFR-mutated and wildtype disease, respectively, $p=0.51)$. No significant difference was noted between groups with cases of nonpulmonary disease recurrence. The most common sites of distant metastatic disease in the EGFR-mutated group included the lung $(n=18 ; 58 \%)$, pleura $(n=10 ; 32 \%)$, and brain $(n=8 ; 26 \%)$. The most common sites of distant metastatic disease in the $E G F R$-wildtype group were lung $(n=9 ; 43 \%)$, lymph nodes $(n=9 ; 43 \%)$, and brain $(n=5$; $24 \%$ ) (Table 3). Although our study was not powered to compare sites of distant metastatic disease, no significant difference was noted in sites of distant metastatic disease between groups.

Analyses of EGFR mutation type were also performed (Table 4). The most common mutations overall were Exon 19 deletions (44\%) and L858R (35\%). Roughly $70 \%$ of both these mutations presented as stage 1 ; however this may represent the larger number of stage 1 disease within our cohort. Only 2 cases had the T790M mutation and only 5 cases of multiple EGFR mutations occurring within one case were noted.

\section{DISCUSSION}

Our study reports a novel finding of increased metastatic recurrence in patients with early and locally advanced $E G F R$-mutated NSCLC undergoing definitive therapy compared to EGFR-wildtype disease. The increased rate of metastatic recurrence found is consistent with prior multi-variate analysis showing decreased relapse-free survival in cases of EGFR-mutated disease $[19,20]$. We did not observe any statistically significant change to survival based on EGFR status (PFS 59\% in $E G F R$-mutant vs $60 \%$ in $E G F R$-wildtype at 5 years). This supports prior investigation showing no prognostic value of EGFR mutation in early stage lung cancer [21]. Overall our findings suggest that while $E G F R$ mutation status does not affect overall recurrence or survival, metastatic vs local recurrence may be influenced by tumor molecular genetics.

The reasons for the high rate of recurrence in early and locally advanced NSCLC after definitive therapy are not completely clear. One theory suggests that most of our standard diagnostic tools for TNM staging, including CT and PET scans, are not sensitive enough to detect distant micro-metastasis present at time of initial diagnoses. 


\begin{tabular}{|c|c|c|c|}
\hline & EFGR Positive $=142$ & EGFR negative $=140$ & $P$-value \\
\hline Overall Recurrence (All stage), $N(\%)$ & 32 & 29 & \\
\hline Stage $1, N(\%)$ & 18 & 12 & \\
\hline Stage $2, N(\%)$ & 2 & 7 & \\
\hline Stage $3, N(\%)$ & 12 & 10 & \\
\hline Metastatic Recurrence among those who recurred, $N(\%)$ & $31(97 \%)$ & $21(68 \%)$ & 0.007 \\
\hline Stage $1, N(\%)$ & $17(94 \%)$ & $6(50 \%)$ & 0.02 \\
\hline Stage $2, N(\%)$ & $2(100 \%)$ & $6(86 \%)$ & $>0.99$ \\
\hline Stage $3, N(\%)$ & $12(100 \%)$ & $9(75 \%)$ & 0.22 \\
\hline \multirow{3}{*}{$\begin{array}{l}\text { Number of sites of metastasis for those with metastatic } \\
\text { recurrence, } N(\%)\end{array}$} & 1: $21(68 \%)$ & 1: $11(52 \%)$ & 0.09 \\
\hline & $2: 4(13 \%)$ & $2: 8(38 \%)$ & \\
\hline & $3+: 6(19 \%)$ & $3+: 2(10 \%)$ & \\
\hline 1 & $21(68 \%)$ & $11(52 \%)$ & \\
\hline 2 & $4(13 \%)$ & $8(38 \%)$ & \\
\hline $3+$ & $6(19 \%)$ & $2(10 \%)$ & \\
\hline $\begin{array}{l}\text { Progression free survival rates, based on Kaplan-Meier } \\
\text { method }(95 \% \mathrm{CI}) \text { for All Stages: }\end{array}$ & & & $>0.99$ \\
\hline 1 year (52 weeks) & $0.94(0.89,0.98)$ & $0.91(0.86,0.96)$ & \\
\hline 2 year (104 weeks) & $0.83(0.76,0.91)$ & $0.81(0.74,0.89)$ & \\
\hline 5 year (260 weeks) & $0.59(0.47,0.73)$ & $0.60(0.50,0.73)$ & \\
\hline $\begin{array}{l}\text { Median Progression Free Survival (IQR) in weeks (All } \\
\text { stages) }^{*}\end{array}$ & N/A $(193, N / A)$ & N/A $(260, N / A)$ & \\
\hline Stage 1 & N/A (N/A, N/A) & N/A (N/A, N/A) & \\
\hline Stage 2 & N/A $(186, N / A)$ & $144(52, \mathrm{~N} / \mathrm{A})$ & \\
\hline Stage 3 & 137 (81, N/A) & $167(85, \mathrm{~N} / \mathrm{A})$ & \\
\hline
\end{tabular}

"Due to insufficient number of events, point estimates and/or confidence interval bounds were not defined for all cases; these cases are marked as "N/A."

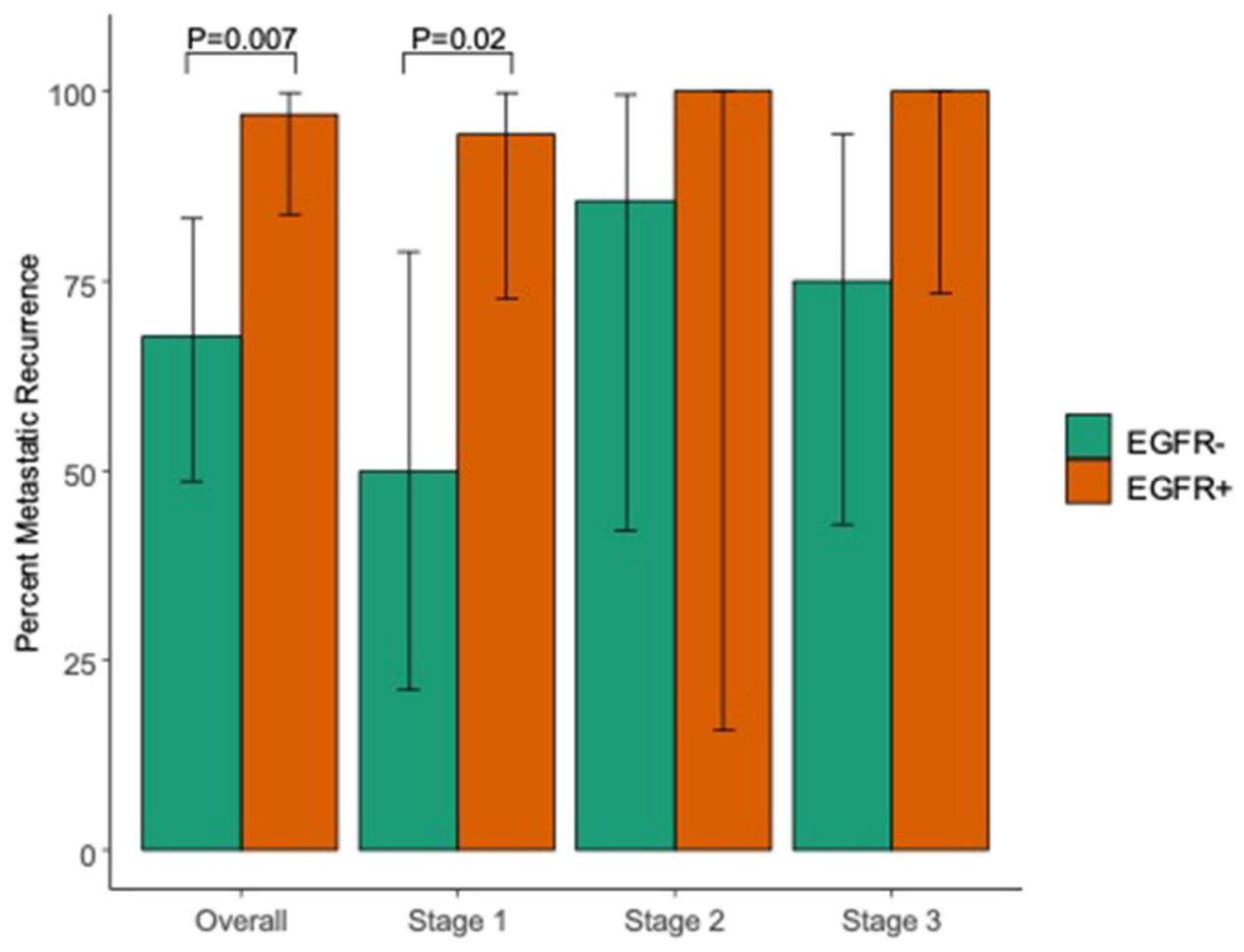

Figure 1: Percent of patients with metastatic disease at recurrence based on initial staging and presence of an $E G F R$ driver mutation. Percent metastatic recurrence among those who recurred by EGFR status and initial stage. 


\begin{tabular}{lccc}
\hline & EGFR Mutated & EGFR Wildtype & $P$-value \\
\hline $\begin{array}{l}\text { Proportion with lung-only } \\
\text { metastasis among those with }\end{array}$ & $8(26 \%)$ & $3(14 \%)$ & 0.51 \\
metastasis, $N(\%)$ & & \\
$\quad$ Stage 1 & $6(35 \%)$ & $1(17 \%)$ & 0.74 \\
$\quad$ Stage 2 & $0(0 \%)$ & $1(17 \%)$ & $>0.99$ \\
$\quad$ Stage 3 & $2(17 \%)$ & $1(11 \%)$ & $>0.99$ \\
Metastatic site in those with & & & \\
metastasis, $N(\%)$ & $18(58 \%)$ & $9(43 \%)$ & 0.43 \\
Lung & $4(13 \%)$ & $1(5 \%)$ & 0.62 \\
Liver & $6(19 \%)$ & $3(14 \%)$ & 0.92 \\
Bone & $1(3 \%)$ & $1(5 \%)$ & $>0.99$ \\
Adrenal & $8(26 \%)$ & $5(24 \%)$ & $>0.99$ \\
Brain & $10(32 \%)$ & $2(10 \%)$ & 0.12 \\
Pleura & $0(0 \%)$ & $1(5 \%)$ & 0.84 \\
Soft tissue & $5(16 \%)$ & $9(43 \%)$ & 0.07 \\
Lymph node & $0(0 \%)$ & $1(5 \%)$ & 0.84 \\
Thyroid & $0(0 \%)$ & $1(5 \%)$ & 0.84 \\
Gastrointestinal tract & $1(3 \%)$ & $0(0 \%)$ & $>0.99$ \\
Pericardium & & & \\
\hline
\end{tabular}

This would cause a fundamental under-estimation of tumor burden and extent of disease [11]. Studies have also demonstrated direct evidence of increased tumor cell burden within the pulmonary veins during lobectomy in surgically resectable primary lung cancer, suggesting that surgical manipulation may cause intraoperative tumor cell "spillage" serving as niduses for disease recurrence [22]. Further studies will need to help elucidate the clinical significance of these disseminated tumor cells given the inconclusive evidence of whether these cells actually express a proliferative phenotype versus a "dormant" one [23].

Either of the above mechanisms could help explain the observed higher rates of metastatic recurrence in $E G F R$-mutated disease. For instance, it is possible that the $E G F R$-mutated phenotype results in a unique tumor physiology that results in higher rates of microscopic foci of disease, even at a clinically low stage. These sites of micro-metastatic disease in EGFR-mutated tumors likely represents a more systemic disease process in contrast to more localized disease process or field cancerization found in $E G F R$-wildtype disease. An alternative explanation may be that $E G F R$ mutated tumors tend to have more tumor cell "spillage" during or prior to surgery, as indicated in prior studies, which in turn results in increased rates of metastatic recurrence [11, 22]. This explanation is further supported by the overwhelming recurrence in lung parenchyma and pleura observed in the EGFR-mutated group, as these sites would be most affected by increased tumor cell burden in pulmonary veins. Furthermore, our study was not powered to detect statistically significant differences in sites of metastatic disease between groups. Additional large observational cohort studies are needed to help determine whether the more systemic nature of $E G F R$-mutated tumors affects sites of metastatic disease at time of first recurrence.

This study showed no statistically different progression free survival between EGFR-mutated and negative groups. We were unable to calculate median progression free survival time in the overall cohort due to insufficient follow-up time; however, median progression free survival was similar among those with stage III disease. Future study of recurrence rates in early and locally advanced NSCLC involving large prospective and multi-center cohorts is needed to validate these results.

Currently, molecular testing in NSCLC is FDAapproved for metastatic NSCLC, but it is not routinely performed in early and locally advanced disease. Additionally, only radiographic guidelines exist for monitoring disease recurrence following definitive surgical therapy in lung cancer. This may not be sufficient for detecting disease which may be intrinsically more systemic and diffuse in nature [24]. The increased rate of metastatic recurrence in EGFR-mutated disease found in this study suggests both distinct tumor physiology as well as a need for earlier use of tumor molecular genetics. These patients may also require more stringent monitoring following curative treatment, as early detection of these recurrences can lead to initiation of treatment. In fact, multiple studies have demonstrated improved post-relapse 
Table 4: EGFR mutation subtypes

\begin{tabular}{|c|c|c|}
\hline Exon Mutation Subtype & $N(\%)$ & Stage at Presentation \\
\hline \multirow[t]{3}{*}{ Exon 19 deletion } & $63(44)$ & Stage $1=48(76 \%)$ \\
\hline & & Stage $2=7(11 \%)$ \\
\hline & & Stage $3=8(13 \%)$ \\
\hline \multirow[t]{3}{*}{ Exon 20 insertion } & $7(5)$ & Stage $1=4(57 \%)$ \\
\hline & & Stage $2=0(0 \%)$ \\
\hline & & Stage $3=3(43 \%)$ \\
\hline \multirow[t]{3}{*}{ G719A } & $2(1)$ & Stage $1=2(100 \%)$ \\
\hline & & Stage $2=0(0 \%)$ \\
\hline & & Stage $3=0(0 \%)$ \\
\hline \multirow[t]{3}{*}{ L858R } & $49(35)$ & Stage $1=34(70 \%)$ \\
\hline & & Stage $2=5(10 \%)$ \\
\hline & & Stage $3=10(20 \%)$ \\
\hline \multirow[t]{3}{*}{ G719× } & $6(4)$ & Stage $1=6(100 \%)$ \\
\hline & & Stage $2=0(0 \%)$ \\
\hline & & Stage $3=0(0 \%)$ \\
\hline \multirow[t]{3}{*}{ L861Q } & $8(6)$ & Stage $1=7(88 \%)$ \\
\hline & & Stage $2=0(0 \%)$ \\
\hline & & Stage $3=1(12 \%)$ \\
\hline \multirow[t]{3}{*}{$\mathrm{T} 790 \mathrm{M}$} & $2(1)$ & Stage $1=2(100 \%)$ \\
\hline & & Stage $2=0(0 \%)$ \\
\hline & & Stage $3=0(0 \%)$ \\
\hline \multirow[t]{3}{*}{ Multiple mutations } & $5(4)$ & Stage $1=4(80 \%)$ \\
\hline & & Stage $2=1(20 \%)$ \\
\hline & & Stage $3=0(0 \%)$ \\
\hline
\end{tabular}

survival compared to wildtype $[19,25,26]$ in $E G F R$ mutated disease, likely due to response to TKI targeted therapies [27].

In summary, this study suggests EGFR mutation as an important marker for predicting metastatic disease recurrence and highlights the growing need for precision medicine in early and locally advanced NSCLC. Early identification of these recurrences is paramount given the improved post-relapse survival observed in this population. A better understanding of the factors leading to relapse rates using prospective, multi-center investigations could help guide future surveillance practices, identify those patients at higher risk, and ultimately extend patient survival.

\section{MATERIALS AND METHODS}

\section{Patients}

We retrospectively identified 142 patients between the ages of 18-99 years with pathologically confirmed EGFR-mutated adenocarcinoma at the McGaw Medical Center of Northwestern University from 2007 to 2018.
These patients were identified based on individual chart review of all NSCLC patients who had positive tumor molecular genetics. Only those patients who had biopsyproven EGFR mutations at time of diagnosis were included. Additionally, patients who were lost to followup, presented with metastatic disease, or did not undergo treatment with curative intent at time of initial diagnosis were excluded.

We also randomly identified 140 patients between the ages of 18-99 years with EGFR wildtype lung adenocarcinoma as controls. Similar to the EGFRmutated cohort, those included in the cohort underwent tumor molecular genetics at time of diagnosis, had nonmetastatic disease at presentation, and underwent definitive management. Similarly, those who were lost to follow-up, presented with metastatic disease, or did not undergo definitive therapy were excluded from the cohort.

\section{Molecular assays}

All molecular genetic testing was done on samples from formalin-fixed paraffin embedded lung tissue specimens. Macrodissection was used for tumor 
enrichment when needed to ensure greater than $10 \%$ tumor cellularity. DNA extraction and purification was performed on automated nucleic extraction instrument QIAsymphony SP using QIAsymphony DNA Mini Kit (Qiagen, Valencia, CA, USA). Before July 2015, the $E G F R$ testing was performed using EGFR Mutation realtime PCR Analysis Kit (EntroGen, Tarzana, CA, USA) following the manufacturer's protocol. After July 2015, EGFR mutations were detected using the Ion AmpliSeq Colon and Lung Cancer Research Panel v2. This panel is an amplicon based next generation sequencing assay (NGS), consisting of 22 targeted genes. Sensitivity of detection was set at $5 \%$ mutant allele or $10 \%$ tumor DNA.

\section{Clinicopathologic characteristics}

We assessed age of diagnosis, gender, NSCLC histology, stage at diagnosis, EGFR status at time of diagnosis, specific EGFR mutation type where applicable, presence of high-risk pathologic features upon surgery and type of definitive treatment. Identified cases were then retrospectively chart-reviewed for presence of pathologically confirmed recurrence, stage of recurrence, time from definitive treatment to recurrence, and overall progression-free survival at 1,2 and 5 years. Stage at diagnosis was calculated using the TNM staging system defined by the American Joint Committee on Cancer 8th edition [28]. Progression was defined as recurrence (local or metastatic) or death by any cause. Progression-free survival was calculated based on Kaplan-Meier methods. Association between categorical variables was performed using chi-square or Wilcoxon sum test where applicable. Patient cases were also evaluated for delivery of standard of care treatment, defined using NCCN guidelines [29]. More specifically, patients with stage I disease received definitive therapy with either surgery or radiotherapy. Stage II disease received surgery or radiation followed by adjuvant chemotherapy. Management of stage III disease involves a multi-disciplinary treatment plan largely depending on surgical resectability. Patients with resectable disease received neoadjuvant chemotherapy $+/-$ radiation followed by surgery $+/-$ adjuvant radiation (if not previously received). For unresectable disease, patients received chemoradiation followed by immunotherapy. All tests were two-sided and $p$-values $<0.05$ were considered statistically significant. All statistical analyses were performed using R 3.4.1.

\section{CONFLICTS OF INTEREST}

None.

\section{REFERENCES}

1. Bray F, Ferlay J, Soerjomataram I, Siegel RL, Torre LA, Jemal A. Global cancer statistics 2018: GLOBOCAN estimates of incidence and mortality worldwide for 36 cancers in 185 countries. CA Cancer J Clin. 2018; 68:394424. https://doi.org/10.3322/caac.21492. [PubMed]

2. WHO International Agency for Research on Cancer. 2018.

3. Blandin Knight S, Crosbie PA, Balata H, Chudziak J, Hussell T, Dive C. Progress and prospects of early detection in lung cancer. Open Biol. 2017; 7:170070. https://doi. org/10.1098/rsob.170070. [PubMed]

4. Lortet-Tieulent J, Soerjomataram I, Ferlay J, Rutherford M, Weiderpass E, Bray F. International trends in lung cancer incidence by histological subtype: adenocarcinoma stabilizing in men but still increasing in women. Lung Cancer. 2014; 84:13-22. https://doi.org/10.1016/j.lungcan.2014.01.009. [PubMed]

5. Cheng TY, Cramb SM, Baade PD, Youlden DR, Nwogu C, Reid ME. The International Epidemiology of Lung Cancer: Latest Trends, Disparities, and Tumor Characteristics. J Thorac Oncol. 2016; 11:1653-71. https://doi.org/10.1016/j. jtho.2016.05.021. [PubMed]

6. National Cancer Institute. SEER stat fact sheets: lung and bronchus cancer. May 1, 2020. Available from: https://seer. cancer.gov/statfacts/html/lungb.html.

7. Darling GE, Allen MS, Decker PA, Ballman K, Malthaner RA, Inculet RI, Jones DR, McKenna RJ, Landreneau RJ, Rusch VW, Putnam JB Jr. Randomized trial of mediastinal lymph node sampling versus complete lymphadenectomy during pulmonary resection in the patient with $\mathrm{N} 0$ or N1 (less than hilar) non-small cell carcinoma: results of the American College of Surgery Oncology Group Z0030 Trial. J Thorac Cardiovasc Surg. 2011; 141:662-70. https://doi. org/10.1016/j.jtcvs.2010.11.008. [PubMed]

8. van den Berg LL, Klinkenberg TJ, Groen HJ, Widder J. Patterns of Recurrence and Survival after Surgery or Stereotactic Radiotherapy for Early Stage NSCLC. J Thorac Oncol. 2015; 10:826-31. https://doi.org/10.1097/ JTO.0000000000000483. [PubMed]

9. al-Kattan K, Sepsas E, Fountain SW, Townsend ER. Disease recurrence after resection for stage I lung cancer. Eur J Cardiothorac Surg. 1997; 12:380-4. https://doi.org/10.1016/ S1010-7940(97)00198-X. [PubMed]

10. Hoffman PC, Mauer AM, Vokes EE. Lung cancer. Lancet. 2000; 355:479-85. https://doi.org/10.1016/S0140-6736(00)82038-3. [PubMed]

11. Uramoto H, Tanaka F. Recurrence after surgery in patients with NSCLC. Transl Lung Cancer Res. 2014; 3:242-9. https://doi. org/10.3978/j.issn.2218-6751.2013.12.05. [ [PubMed]

12. Hoang JK, Patz E Jr, Giroux D, Goldstraw P. Frequency and prognostic significance of preoperatively detected enlarged regional lymph nodes in patients with pathological stage I non-small cell lung cancer following resection. J Thorac Oncol. 2007; 2:1103-6. https://doi.org/10.1097/ JTO.0b013e31815c04b4. [PubMed]

13. Martin J, Ginsberg RJ, Venkatraman ES, Bains MS, Downey RJ, Korst RJ, Kris MG, Rusch VW. Long-term 
results of combined-modality therapy in resectable nonsmall-cell lung cancer. J Clin Oncol. 2002; 20:1989-95. https://doi.org/10.1200/JCO.2002.08.092. [ubMed]

14. Martini N, Bains MS, Burt ME, Zakowski MF, McCormack P, Rusch VW, Ginsberg RJ. Incidence of local recurrence and second primary tumors in resected stage I lung cancer. J Thorac Cardiovasc Surg. 1995; 109:120-9. https://doi. org/10.1016/S0022-5223(95)70427-2. [PubMed]

15. Sugimura H, Nichols FC, Yang $\mathrm{P}$, Allen MS, Cassivi SD, Deschamps C, Williams BA, Pairolero PC. Survival after recurrent nonsmall-cell lung cancer after complete pulmonary resection. Ann Thorac Surg. 2007; 83:409-17. https://doi.org/10.1016/j.athoracsur.2006.08.046. [PubMed]

16. Shigematsu H, Lin L, Takahashi T, Nomura M, Suzuki M, Wistuba, II, Fong KM, Lee H, Toyooka S, Shimizu N, Fujisawa T, Feng Z, Roth JA, et al. Clinical and biological features associated with epidermal growth factor receptor gene mutations in lung cancers. J Natl Cancer Inst. 2005; 97:339-46. https://doi.org/10.1093/jnci/dji055. [PubMed]

17. Shi Y, Au JS, Thongprasert S, Srinivasan S, Tsai CM, Khoa MT, Heeroma K, Itoh Y, Cornelio G, Yang PC. A prospective, molecular epidemiology study of EGFR mutations in Asian patients with advanced non-small-cell lung cancer of adenocarcinoma histology (PIONEER). J Thorac Oncol. 2014; 9:154-62. https://doi.org/10.1097/ JTO.0000000000000033. [PubMed]

18. Mayekar MK, Bivona TG. Current Landscape of Targeted Therapy in Lung Cancer. Clin Pharmacol Ther. 2017; 102:757-64. https://doi.org/10.1002/cpt.810. [PubMed]

19. Ito M, Miyata Y, Hirano S, Kimura S, Irisuna F, Ikeda K, Kushitani K, Kishi N, Tsutani Y, Takeshima Y, Okada M. Synchronicity of genetic variants between primary sites and metastatic lymph nodes, and prognostic impact in nodal metastatic lung adenocarcinoma. J Cancer Res Clin Oncol. 2019; 145:2325-2333. https://doi.org/10.1007/s00432-01902978-0. [PubMed]

20. Ito M, Miyata Y, Kushitani K, Yoshiya T, Kai Y, Tsutani Y, Mimura T, Konishi K, Takeshima Y, Okada M. Increased risk of recurrence in resected EGFR-positive pNOM0 invasive lung adenocarcinoma. Thorac Cancer. 2018; 9:1594-602. https://doi.org/10.1111/1759-7714.12866. [PubMed]

21. He Q, Xin P, Zhang M, Jiang S, Zhang J, Zhong S, Liu Y, Guo M, Chen X, Xia X, Pan Z, Guo C, Cai X, et al. The impact of epidermal growth factor receptor mutations on the prognosis of resected non-small cell lung cancer: a meta-analysis of literatures. Transl Lung Cancer Res. 2019; 8:124-34. https://doi.org/10.21037/tlcr.2019.03.14. [PubMed]
22. Hashimoto M, Tanaka F, Yoneda K, Takuwa T, Matsumoto S, Okumura Y, Kondo N, Tsubota N, Tsujimura T, Tabata C, Nakano T, Hasegawa S. Significant increase in circulating tumour cells in pulmonary venous blood during surgical manipulation in patients with primary lung cancer. Interact Cardiovasc Thorac Surg. 2014; 18:775-83. https://doi. org/10.1093/icvts/ivu048. [PubMed]

23. Rud AK, Borgen E, Maelandsmo GM, Flatmark K, Le H, Josefsen D, Solvoll I, Schirmer CB, Helland A, Jorgensen L, Brustugun OT, Fodstad O, Boye K. Clinical significance of disseminated tumour cells in non-small cell lung cancer. Br J Cancer. 2013; 109:1264-70. https://doi.org/10.1038/ bjc.2013.450. [PubMed]

24. Network NCC. Non-Small Cell Lung Cancer (Version 6.2019). August 12, 2019. Available from: https://www. nccn.org/professionals/physician_gls/pdf/nscl.pdf.

25. Isaka T, Nakayama H, Ito H, Yokose T, Yamada K, Masuda M. Impact of the epidermal growth factor receptor mutation status on the prognosis of recurrent adenocarcinoma of the lung after curative surgery. BMC Cancer. 2018; 18:959. https://doi.org/10.1186/s12885-018-4849-9. [PubMed]

26. Liu WS, Zhao LJ, Pang QS, Yuan ZY, Li B, Wang P. Prognostic value of epidermal growth factor receptor mutations in resected lung adenocarcinomas. Med Oncol. 2014; 31:771. https://doi.org/10.1007/s12032-013-0771-9. [PubMed]

27. Jeon JH, Kang CH, Kim HS, Seong YW, Park IK, Kim YT. Prognostic and predictive role of epidermal growth factor receptor mutation in recurrent pulmonary adenocarcinoma after curative resection. Eur J Cardiothorac Surg. 2015; 47:556-62. https://doi.org/10.1093/ejcts/ezu177. [PubMed]

28. Amin MB, Edge S, Greene F, Byrd DR, Brookland RK, Washington MK, Gershenwald JE, Compton CC, Hess KR, Sullivan DC, Jessup JM, Brierley JD, Gaspar LE, et al, and American Joint Committee on Cancer and American Cancer Society. AJCC cancer staging manual. 8th ed. 2017. Chicago, Springer.

29. Network NCC. Non-Small Cell Lung Cancer (Version 5.2019). 2019. Available from: https://www.ncen.org/ professionals/physician gls/pdf/nscl.pdf. 